\section{¿Qué nos puede decir de los médicos el Registro} de Prestadores individuales?

\section{What can the Provider's Register tell us about physicians?}

\section{Sr. Editor}

Garantizar el acceso a la Salud en una sociedad que demanda servicios resolutivos y de calidad es un desafío complejo, que requiere de un permanente análisis de sus diversos determinantes, entre ellos, el recurso humano existente.

En nuestro país, la estimación del personal médico, principalmente de los especialistas, tiene limitaciones, pese a que se han elaborado metodologías tales como la propuesta del Banco Mundial ${ }^{1}$ y otras ${ }^{2}$. $\mathrm{Al}$ respecto, resulta importante no sólo la determinación de la brecha de profesionales, sino que también conocer las variables que podrían condicionar aspectos como el ingreso, movilidad, permanencia laboral y capacitación de éstos, aportando mayor y mejor información a los distintos agentes involucrados en la respuesta sanitaria, con fines investigativos y/o elaboración de políticas públicas. Todo ello en un ambiente de marcado aumento de matrícula universitaria, participación femenina e importante alza de inmigración profesional.

El Registro Nacional de Prestadores Individuales de Salud (RNPI) se define como una herramienta que permite consultar si un profesional de la salud está legalmente habilitado para ejercer su profesión en el país, con el fin de otorgar seguridad sobre la idoneidad técnica sanitaria de ese profesional. Actualmente dicho registro es considerado la base de datos de profesionales más confiable, masiva y fidedigna existente en nuestro país. En ese marco, el estudio y análisis básico de dicho RNPI, nos muestra hechos que, si bien son conocidos principalmente por los gremios, rara vez son objetivados y/o son publicados en literatura convencional, dejando abierta la posibilidad de plantearse importantes interrogantes.

Un buen ejemplo de ello es preguntarse ¿cuántas médicos mujeres hay en Chile? aún con riesgo de subestimar $^{3}$, a Mayo del 2016, existían 39.880 registros de médicos, vivos, con un promedio de edad 39,5 años $( \pm 13,5)$ y un índice de feminidad de 45,8 promedio, en sostenido aumento. Ante tales incrementos, sería interesante estudiar sus características, la evolución de este aumento, así como la existencia de correlaciones con el salario ${ }^{4}$, pues en un análisis de universitarios chilenos, Schurch ya estimó que la feminización de las carreras "se relacionan negativamente con las remuneraciones de los titulados, incluso luego de controlar un conjunto de características individuales como el género, el origen social $y$ el desempeño universitario ${ }^{5}$ ".

Otro dato a analizar es el registro de profesionales médicos extranjeros. Es conocido que su ingreso al país ha ido en aumento, correspondiendo a $14,8 \%$ de los médicos, pero sólo $6,6 \%$ de ellos está registrado como especialista. Sin embargo, 21,3\% de los títulos convalidados corresponden a chilenos. ¿Qué razones hay para que compatriotas estudien fuera y vuelvan a ejercer en el país? Es una interesante pregunta, pero lo es aún más el saber si es una tendencia ascendente o descendente y si existirán diferencias significativas en el resultado del EUNACOM.

Respecto a las formas de convalidar el título de médico, es de notar, que sólo 11 de las 15 Secretarías Regionales Ministeriales (SEREMIS) otorguen reconocimientos profesionales, cuatro de las cuales (Coquimbo, Maule, Los Lagos, Bio Bio) concentran $74,9 \%$ de las registrados bajo esta modalidad. ¿Podría ser este un indicador de que son las regiones con más falencia de médicos?

Según el RNPI, 21.361 (64,6\%) de los inscritos son especialistas, pero existe un número mayor de registros de especialidad (25.774). Este diferencial, observado entre el número de RUT de prestadores especialistas registrados versus el total de registros de especialidad existentes, se origina al existir profesionales que poseen más de una especialidad o subespecialidad, pero también porque existen profesionales que, en virtud de la normativa vigente, han efectuado su certificación de especialidad por más de una vía. Esta situación, si bien es administrativamente correcta, distorsiona los valores a analizar y, de no ser evaluada correctamente, sobreestima el número de especialistas en el país ${ }^{6,7}$.

El año 2013, el Decano de Medicina de la Universidad Católica ${ }^{8}$, estimó un déficit de médicos especialistas de 1.500 profesionales. Sin embargo, el análisis del registro indica que el $64,6 \%$ de los especialistas corresponde a solo 10 de las 62 especialidades médicas certificables, en franco desmedro de otras, tales como reumatología y ginecología pediátrica.Tal vez no sea suficiente solo cuantificar la brecha si no también caracterizarla.

Para finalizar, en nuestra opinión, existe un amplio campo de investigación asociado a la caracterización de los profesionales de la salud, que se encuentra poco explorado. Profundizar en estos temas nos permitiría mejorar la gestión del recurso humano médico. En ese contexto, el RNPI constituyeuna valiosa fuente de información, la cual podría ser aún más provechosa si se explotaran todas sus potencialidades, como por ejemplo, registrar el lugar de desempeño.

Karla Moscoso-Matus ${ }^{1,2, a}, \begin{array}{r}\text { Marco Cornejo-Ovalle } \\ \text { Mario Flores Ferretto }\end{array}$
Mala
${ }^{1}$ Unidad Auditoría Interna. Servicio Médico Legal.
Santiago. Chile.
${ }^{2}$ Facultad de Odontología. Universidad de Chile.
Santiago. Chile.
${ }^{3}$ Facultad de Odontología. Universidad San Sebastián.
Puerto Montt. Chile.
${ }^{a}$ Cirujano Dentista
${ }^{b}$ Cirujano Dentista, PhD en Salud Pública.




\section{Referencias}

1. Ministerio de Salud, Banco Mundial. Estudio de brechas de oferta y demanda de médicos especialistas en Chile. Colaboración técnica del Banco Mundial y el Gobierno de Chile. Informe final. Buenos Aires: Banco Mundial; 2009.

2. Guillou M., Carabantes J., Bustos, V. Disponibilidad de médicos y especialistas en Chile. Rev Med Chile 2011; 139 (5): 559-70.

3. Moscoso-Matus K, Smok P, Botto A. Odontólogos del Registro Nacional de Prestadores Individuales de Salud. Rev Clin Periodoncia Implantol Rehabil Oral 2016; 9 (1): 42-7.

4. Connolly S, Holdcroft A. The Pay Gap for Women in Medicine and Academic Medicine. An analysis of the WAM* database. British Medical Association. 2009. http://www. medicalwomensfederation.org.uk/images/Daonload_Pay_ Gap_Report.pdf (Consultado el 17 de agosto de 2016).

5. Schurch R. El retorno de las carreras: Un estudio de casos de los factores que inciden en las remuneraciones de universitarios recién titulados. Revista Calidad en la Educación, No 38, julio 2013. http://www.cned.cl/public/secciones/
SeccionRevistaCalidad/revista_calidad_leer_revista.aspx?idPublicacion=76 (Consultado el 21 de septiembre de 2016).

6. Decreto Supremo No 8. Reglamento de certificación de las especialidades de los prestadores de salud y de las entidades que lo otorgan. 5 de febrero 2013. Ministerio de Salud. http://web.minsal.cl/portal/url/item/e12ac90f29b1a340e04001016401567d.pdf (Consultado el 8 de junio de 2015).

7. Decreto Supremo No 65. Modifica Decreto Supremo No8 Reglamento de certificación de las especialidades de los prestadores de salud y de las entidades que lo otorgan. $26 \mathrm{de}$ mayo 2015. Ministerio de Salud. http://web.minsal.cl/sites/ default/files/DTO-65_13-AGO-2015.pdf (Consultado el 8 de junio de 2016).

8. Ibáñez C. Necesidad de médicos especialistas de calidad. Carta al editor. Rev Chil Cir 2013; 65 (6): 485-6.

Correspondencia:

Dra. Karla Moscoso Matus

Teatinos \#240, Santiago, Chile.

kmoscoso@gmail.com 